\title{
Parasite transmission between soft-bottom invertebrates: temperature mediated infection rates and mortality in Corophium volutator
}

\author{
Kim N. Mouritsen ${ }^{*}$, K. Thomas Jensen \\ Department of Marine Ecology, Institute of Biological Sciences, University of Aarhus, Einlandsgade 14, \\ DK-8200 Aarhus N, Denmark
}

\begin{abstract}
Circumstantial evidence has suggested that marine microphallid trematodes using gastropods Hydrobia spp. as first intermediate hosts, amphipods Corophium spp. as second intermediate hosts, and various waterbirds as final hosts, may cause temperature-dependent epizootics and eventually local extinction of intermediate host populations. Therefore, we examined experimentally the impact of the microphallid trematode Maritrema subdolum on Corophium volutator with special reference to the influence of temperature, during the parasites' transmission from snail to amphipod. Trematode infected snails and amphipods were established together in experimental aquaria at temperatures of 15,22 and $24^{\circ} \mathrm{C}$ for $9 \mathrm{~d}$. Amphıpod surface activity, survival rate, parasite prevalence, infection rate, and parasite distribution both within and between amphipod indıviduals were recorded during, or at the end of, the experiment. The snails' shedding rate of larval tronatodes as a function of temperature was also examined. Increasing temperature resulted in higher infection levels and parasite-induced mortality in the amphipods, most likely governed by a similar temperature-dependent emergence of larval trematodes from the snails. No transmission occurred at $15^{\circ} \mathrm{C}$, whereas at $24^{\circ} \mathrm{C}$ the parasite prevalence approached $100 \%$ and the parasite-induced mortality exceeded $50 \%$ in relation to controls. As assessed by the transparency of the amphipods' gills, infestation inflicted anaemia was the likely mechanism behind the increased surface activity observed among infected specimens. This parasiteinduced behavioural change may facilitate transmission of infective stages to shorebird hosts feeding on $C$. volutator The results demonstrate that microphallid trematodes are able to induce a significant additive mortality in $C$. volutator populations. The temperature mediated mortality emphasizes the potential significance of a density-independent process in controlling the impact of parasites on host organisms and thereby host population dynamics.
\end{abstract}

KEY WORDS: Corophium volutator Parasitism - Mortality - Temperature Population dynamics Behavioural change Microphallids Trematodes. Tidal flat Hydrobia ulvae

\section{INTRODUCTION}

Parasites have increasingly been recognized as agents that interfere with essential aspects of the life of an animal host, including physiology, behaviour, reproduction, competitive ability and survival (e.g. Anderson 1979, May 1983, Sousa 1983, Hamilton et al. 1990, Lively et al. 1990, Møller 1990, Minchella \& Scott 1991, Lively 1992). Nevertheless, parasitism, unlike

\footnotetext{
•E-mail:knm@bio.aau.dk
}

the more commonly studied processes of predation and competition, has received relatively little empirical attention as a factor affecting the dynamics of animal populations or the structure of animal communities (Dobson \& Hudson 1986, Anderson 1991, Minchella \& Scott 1991, Holt 1993). This lack of attention is particularly true for populations of marine soft-bottom invertebrates (Sousa 1991). Most studies on these organisms have merely reported on epizootic outbreaks among introduced or cultured species (see Kinne 1980, 1983, Rohde 1982, and references therein). Few attempts have been made to clarify how parasites invoke signif- 
icant mortality in natural host populations, and experiments clarifying whether parasites induce depensatory, additive or compensatory mortality (the latter having no population dynamic consequences) are lacking in general (see Holmes 1982).

It seems likely that the impact of parasites in softbottom intertidal habitats has been overlooked rather than that parasites are noninfluential. Invertebrate populations of intertidal areas often are characterized by apparently erratic fluctuations in densities, due in part to the harsh environmental conditions, but also to periodically strong predation pressures from fish, waterbirds, and predatory invertebrates that may exploit these habitats, especially during certain periods of their life cycles (Reise 1978, 1985, Schneider 1978, Commito 1982, Kent \& Day 1983, Ambrose 1984, 1991, Quammen 1984, Murdoch et al. 1986, Peer et al. 1986, Wilson 1991). However, parasites commonly use the predator-prey systems for transmission (e.g. Lafferty 1992), which may cause the influence of the parasites to remain largely undetected. 'We see predators kill, but rarely parasites' (Price 1980).

The small and often abundant amphipod Corophium volutator inhabiting U-shaped burrows in the substrate of near-shore soft-sediment environments is regularly subjected to large and often unexplained fluctuations in population densities (see Watkin 1941, Reise 1978, 1985, Fish \& Mills 1979, Möller \& Rosenberg 1982, Murdach et al, 1986, Olafsson \& Persson 1986, Wilson 1989, Matthews et a1. 1992). Parasites have previously been suggested to curtail Corophium survival (Muus 1967, Lauckner 1987), and more recently Jensen \& Mouritsen (1992) ascribed the local extinction of an intertidal population of $C$. volutator to an epizootic caused by the microphallid trematodes Maritrema subdolum Jaegerskioeld, 1909 and Microphallus claviformis (Brandes, 1888). These digenean parasites are engaged in complex life cycles using various waterbirds as final hosts, mud snails Hydrobia spp. as first intermedjate hosts, and Corophium spp. as second intermediate hosts (e.g. Lauckner 1987). The adult trematodes inhabit the final host's intestine. Their eggs are expelled to the exterior with the birds' faeces and some are eventually consumed by Hydrobia spp. snails. Within the gonads of the snails, the larval trematodes multiply asexually into numerous cercariae that leave the snail host in order to penetrate and encyst as metacercariae within the body cavity of Corophium spp. The infective metacercariae are transmitted to the bird when it feeds on these amphipods.

Jensen \& Mouritsen (1992) hypothesized that the occurrence of unusually high temperatures and an accompanying high prevalence of microphallids in the coexisting population of Hydrobia ulvae caused a mass development of cercariae that upon transmission in- flicted severe pathogenic damage to the amphipods, eventually causing extinction of the local Corophium volutator population.

The present study presents data on 3 crucial characteristics of this host-parasite association: (1) an experimental test of the potential of microphallid trematodes as agents of additive mortality in Corophium volutatori (2) a specific examination of the relationship between temperature, infection rates and mortality in C. volutator $_{i}$ (3) an elucidation of the process of parasite invasion and the resulting pathological effects and behavioural changes induced in the amphipods. The results are discussed in the context of parasite-induced density-dependent regulation of host populations as opposed to environmentally controlled density-independent determination of host abundance (see Scott \& Dobson 1989).

\section{MATERIALS AND METHODS}

Collection and storage of specimens. Specimens of Hydrobia ulvae were collected during spring and summer 1993 on an intertidal mudflat in the southern part of the Danish Wadden Sea (54 $56^{\prime} N$, $8^{\circ} 39^{\prime}$ E), where the collapse in the sympatric Corophium volutator population was observed previously (Jensen \& Mouritsen 1992). The collected snails were established in the laboratory in aquaria supplied with running sea water and natural substrate containing epipelic diatoms as the food source. Trematode-infected individuals were identified by the shedding of cercariae. Snails were placed individually in small petri dishes under constant light at $25^{\circ} \mathrm{C}$. After $24 \mathrm{~h}$, the petri dishes were inspected through a stereomicroscope, and shed cercariae were identified to species level according to Deblock (1980) using a light microscope. Snails infested with Maritrema subdolum (Fig. 1A) and Himasthla continua (Fig. 1B) were sorted and stored separately.

Because amphipods living sympatrically with Hydrobia ulvae may be naturally infected by larval trematodes, Corophium volutator were collected from an artificial saltwater lagoon situated about $500 \mathrm{~m}$ from the site of snail collection. H. ulvae is very uncommon in this lagoon; consequently, $C$. volutator infected by trematodes using $H$. ulvae as first intermediate host are scarce (authors' pers. obs., and see 'Results'). The amphipods were collected in August 1993, established in the laboratory and held under conditions similar to those of the snails until the start of the experiments.

Experimental design. Small glass jars (0.5 l) were used as experimental aquaria (Fig. 2). Each aquarium was supplied with $5 \mathrm{~cm}$ of sieved sediment and a $3 \mathrm{~cm}$ column of sea water $(\approx 28 \%$ ) aerated via a glass pipette 
mounted in a hole in the lid. As a food source for both amphipods and snails, a 3 to $4 \mathrm{~mm}$ layer of silty sediment, rich in epipelic diatoms, was distributed on the substrate. A mesh container $13.5 \mathrm{~cm}$ in diameter; $1 \mathrm{~mm}$ mesh size) enclosing the snails was pressed into the sediment in the centre of the aquarium. The amphipods were established outside the mesh container. This set-up submerged the snails and allowed shed cercariae to escape from the container. To each aquarium 10 trematodeinfected Hydrobia ulvae and 20 Corophium volutator were added, corresponding to 2000 and 4000 specimens $\mathrm{m}^{-2}$, respectively. Although these densities are below values often encountered in natural populations, the density ratio between $C$. volutator and infected $H$. ulvae is within the range of density ratios previously observed in the field $(0.7$ to 16 ; see e.g. Jensen \& Mouritsen 1992, Mouritsen 1994)

Closed experimental aquaria without water flow do not resemble the range of conditions in the field, but do resemble restricted conditions under which the main transmission of Maritrema subdolum is likely to occur. Release of cercariae from the snails is promoted by high temperatures (see 'Results', Ginetsinskaya 1988, unpubl. data) and, hence, parasite transmission in situ is likely to be especially pronounced in intertidal pools during daylight where solar radiation elevates the water temperature considerably (de Wilde \& Berghuis 1978, Ginetsinskaya 1988).

The Corophium volutator specimens measured $4.5 \pm$ $0.5 \mathrm{~mm}$ (mean $\pm 1 \mathrm{SD}, \mathrm{n}=230$ ) in length (rostrum to telson), and the shell of Hydrobia ulvae had a mean height (apex to aperture) of $4.9 \pm 0.5 \mathrm{~mm}(\mathrm{n}=135$ ). Length measurements on the amphipods were carried out on preserved control specimens (see 'Parasite induced mortality') after experimentation.

Parasite-induced mortality. To examine the effect of temperature on infection rates and mortality in Corophium volutator exposed to Maritrema subdoluminfected snails, 10 aquaria were placed under $24 \mathrm{~h}$ constant light in each of 3 windowless rooms at $15 \pm 1,22 \pm$ 1 and $24 \pm 1^{\circ} \mathrm{C}$, respectively. Two treatments were conducted at each temperature: (1) addition of snails shedding $M$. subdolum cercariae ( $\mathrm{n}=5$ at each temperature), and (2) addition of snails shedding Himasthla continua cercariae ( $\mathrm{n}=5$ at each temperature). Distinguishing between infected and non-infected snails with certainty based on the presence or absence of cercariae emergence can be difficult (Curtis \& Hubbard 1990). Consequently, $H$. continua-infected snails were used in control aquaria rather than 'non-infected' snails, as judged by lack of cercariae production. Like $M$. subdolum, $H$. continua is a digenean, but it has a different life cycle, using molluscs instead of amphipods as the second intermediate host. Hence, larval $H$.

Fig. 2. Glass jar (0.5 l) used as experimental aquarium depicting oxygen supply water level, substrate and the mesh container enclosing the snails

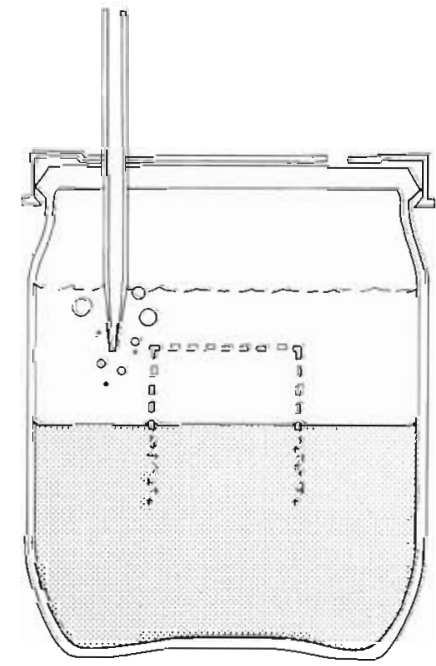


continua are not able to penetrate and encyst in amphipods. Previous experiments have revealed that exposure to cercariae of $H$. continua does not affect the survival rate of $C$. volutator (authors' unpubl. data), thus, $H$. continua-infected snails may be viewed as true controls in the present experiment, as is demonstrated also by the results.

The experimental temperature intervals correspond well to temperatures experienced by the specimens in situ. During the period of May through September in the Danish Wadden Sea, temperatures between 20 and $25^{\circ} \mathrm{C}$ occur regularly in surface sediment and intertidal pools at low water, and temperatures reaching $30^{\circ} \mathrm{C}$ have occasionally been measured during calm and cloudless days (authors' pers, obs.).

During the $9 \mathrm{~d}$ of the experiment, the aquaria were inspected regularly. Dead amphipods on the sediment surface were removed and preserved in $80 \%$ ethanol. At the start (Day 2 in order to let added amphipods establish themselves) and at the end of the experiment (Day 9), the number of surface-active specimens (amphipods that had left their burrows completely) were recorded in each aquarium. Knowing the number of amphipods initially added, and the number retained at the end of the experiment, it is possible to calculate the proportion of surface-active animals for each aquarium at Days 2 and 9 . It is assumed that no mortality occurred between Days 1 and 2 .

At the termination of the experiment, the aquaria were emptied and the remaining amphipods from each container were counted and placed in fresh sea water for an additional $24 \mathrm{~h}$ to allow relocation and encystment of recently penetrated cercariae. The amphipods were then preserved in ethanol and subsequently sexed, measured, and dissected under a stereomicroscope for the presence, number, and position of larval Maritrema subdolum. During dissection it was noticed that infected animals often possessed more transparent gills than uninfected individuals, apparently due to the presence of only very little haemolymph in the gills of infected specimens. To quantify this, one of the hindmost gills of each Corophium volutator specimen was photographed under a light microscope.

Cercarial emergence. To estimate average cercarial production per snail per day at different temperatures, another randomly chosen group of Maritrema subdolum-infected snails from the same field sample was placed individually in small petri dishes supplied with sea water $(\approx 28 \%)$. The snails were separated into 3 groups and left under constant light for $24 \mathrm{~h}$ at $15 \pm 1$, $20 \pm 1$ and $25 \pm 1^{\circ} \mathrm{C}$, respectively. Following removal of the snails and addition of ethanol, the emerged cercariae were counted under a stereomicroscope.

Generally, emergence of larval trematodes from the imdividual snail host is highly variable on a daily basis as well as over a longer period of time (e.g. Theron \& Moné 1984, authors' unpubl. data). Cercarial production estimated from the above counts may therefore depart somewhat from the number actually released during the main experiment. However, to keep the experimental set-up undisturbed, measurements of cercarial emergence were avoided during experimentation.

Route of transmission. In order to elucidate the process of cercariae transmission between snails and amphipods, qualitative observations of the behaviour of cercariae and amphipods during contact were conducted. During a period of 12 to $24 \mathrm{~h}$, recently shed larval trematodes were regularly added to aquaria containing previously established amphipods. Cercariae as well as burrowed and surface active Corophium volutator specimens $(n=10)$ were observed through a horizontally oriented stereomicroscope. The amphipods were subsequently fixed in $80 \%$ ethanol, dissected and examined under a light microscope so that newly entered unencysted cercariae could be located within their bodies. To identify the moment of penetration, a few recently killed amphipods were placed in petri dishes with cercariae and observed through a stereomicroscope.

Data analysis. Statistical analysis was performed using SPSS (Hull \& Nie 1981). Prior to all. main analyses, tests for the assumption of homogeneity of variance was conducted. This assumption was violated in the data of cercarial production, and a $\ln (x+1)$ transformation was carried out to stabilize the variance.

At termination of the main experiment it became clear that one of the aquaria at $24^{\circ} \mathrm{C}$, planned as a control, had been erroneously treated with Maritrema subdolum-infected snails, producing slightly unbalanced data. Ordinary ANOVA was nevertheless performed on these data since alternative methods applied in the case of unbalanced data (Shaw \& Mitchell-Olds 1993) produced similar results by demonstrating highly significant effects. A posteriori planned pair-wise comparisons of means were accordingly performed using Mann-Whitney tests (Day \& Quinn 1989) or, regarding infection rates, Student's ttest for unequal sample size.

Regarding the data on surface activity, a standard ANOVA performed on the unbalanced data was considered inappropriate because of the relatively high and heterogeneous variances and incomplete independence of observations. Hence, an arcsin square root $x$ transformation was performed in addition to random removal of cases thereby balancing the data prior to ANOVA with repeated measures. Although information is lost by removing cases, it was considered a better alternative than addition of cell means. Although statistical analysis was performed on a 
reduced set of data, the graphical presentation of the surface activity incorporates all data available (Fig. 8)

\section{RESULTS}

\section{Cercarial production}

The rate of emergence of Maritrema subdolum cercariae from the infected snails showed a significant positive relationship with temperature (Fig. 3). The relationship is approximately linear (weakly curvilinear) within the applied temperature range with an almost 9 -fold increase in shedding rate per $10^{\circ} \mathrm{C}$.

\section{Route of transmission}

When released from the snail, the cercaria strikes vigorously with the tail which keeps the ventrally bent body swimming without any apparent directional transport. However, in the vicinity of a burrowed Corophium volutator specimen the swimming cercariae were easily dragged into the burrow by the ventilation current produced by the amphipod's abdominal pleopods. Caught in the main ventilation current, the cercariae were transported backwards mainly along the amphipod's ventral side and were

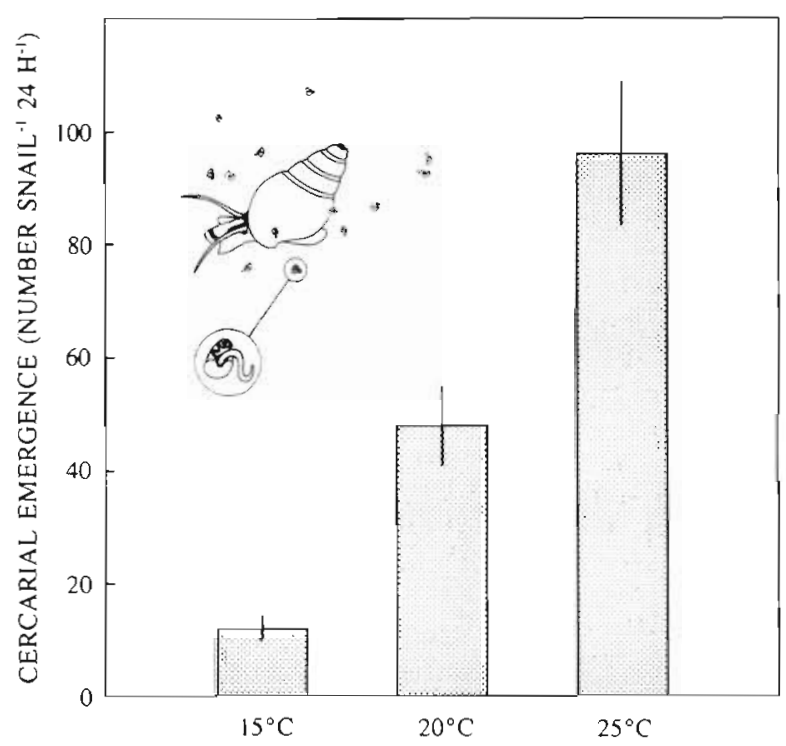

Fig. 3. Maritrema subdolum. Mean number ( $\pm 1 \mathrm{SE}$ ) of emerged cercariae per snail per day at different temperatures. $\mathrm{n}=30$ snails for all values. All mean values differ from each other 11 -way ANOVA on $\ln (x+1)$ transformed data, $F_{2,87}=27.29, \mathrm{p}<0.0001 ;$ LSD a posteriori tests: $p<0.01$ for all possible comparisons] led out especially at the hindmost thoracical appendages. Direct contact between swimming cercariae and the amphipods' smooth cuticula rarely induced penetration attempts. However, if the larvae were accidentally caught between setae or spines, their swimming behaviour was usually replaced by crawling and penetration movements. Within a few seconds the cercariae would lose their tails, penetrate the cuticula, and move easily around within the amphipod's inner tissue.

Recently penetrated and unencysted cercariae were primarily located in the appendages, whereas mesoand metacercariae were situated in the thoracic/ abdominal body segments (Figs. 4 \& 5), indicating that the cercariae invade the amphipods through the legs and subsequently occupy the body cavity. This applies particularly to the hindmost thoracical legs and segments harbouring the highest proportion of larval trematodes (Fig. 4). Initial cercarial invasion through the appendages is consistent with the described act of transmission since the appendages, and especially the hindmost pairs, possess high densities of setae in which the cercariae are easily lodged.

\section{Infection rates and parasite distribution}

Increasing temperature exerted a significant positive influence on infection rates among the surviving Corophium volutator specimens (Fig. 6). No metacercariae were found in control individuals or in Maritrema subdolum exposed C. volutator at $15^{\circ} \mathrm{C}$, whereas the mean number per specimen per aquaria increased from 3.5 at $22^{\circ} \mathrm{C}$ to 11.5 at $24^{\circ} \mathrm{C}$. Considering together all Corophium individuals from each Maritrema treatment ( 5 to 6 aquaria) at 22 and $24^{\circ} \mathrm{C}$, the parasite prevalence and range of parasite numbers per specimen were $80 \%$ and 0 to $30(\mathrm{n}=73)$ at $22^{\circ} \mathrm{C}$ and $97 \%$ and 0 to $40(n=66)$ at $24^{\circ} \mathrm{C}$, respectively.

Also considering together all specimens within each treatment, the coefficient of dispersion $\left(s^{2} / x\right)$ of the number of metacercariae per amphipod individual was on average 6.8 and 5.6 at $22^{\circ}$ and $24^{\circ} \mathrm{C}$, respectively. These figures indicate an overdispersed (= aggregated) parasite distribution at both experimental temperatures (see Anderson \& Gordon 1982, Esch \& Fernández 1993).

Of the dead Corophium volutator specimens collected at the sediment surface during the experiment. only 5 individuals were preserved in a condition adequate for reliable assessment of the pre-mortem mesoor metacercarial numbers. These 5 individuals harboured on average 11.8 cysts (range 4 to 20). Because unencysted cercariae disintegrate rapidly following 


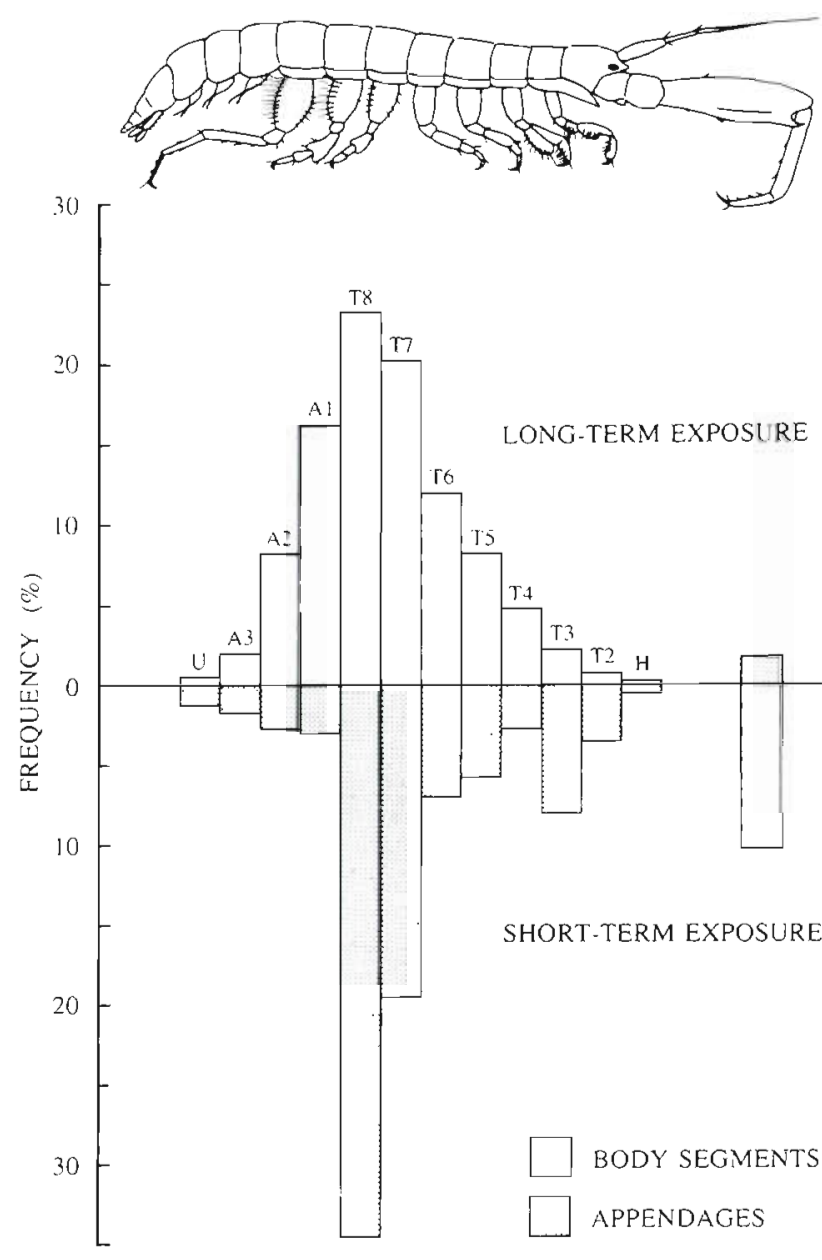

Fig. 4. Corophium volutator. Frequency distribution of metacercariae and unencysted tailless cercariae in different body parts of infected amphipods following a long-term exposure (the main experiment, $\mathrm{n}=122$ amphipods, 955 meso- and metacercariae $e_{i}$ columns above $x$-axis) and a short-term (12 to $24 \mathrm{~h}$ ) intensive exposure to larval Maritrema subdolum ( $\mathrm{n}=10$ amphipods, 374 unencysted cercariae; columns below $x$-axis). $H$ : head; T2-T8: thoracical segments; A1-A3: abdominal segments; $\mathrm{U}$ : urosome

the death of the amphipod (Lauckner 1987), the actual parasite burden of killed specimens may be considerably underestimated.

Infection levels did not differ significantly between sexes, either at $22^{\circ} \mathrm{C}$ (Student's $t$-test, $t_{600}=1.1, p=0.28$ ) or at $24^{\circ} \mathrm{C}\left(t_{57}=0.05, \mathrm{p}=0.96\right)$. There was, however, a significant positive relationship between infection level and amphipod size both at $22^{\circ} \mathrm{C}\left(r_{66}=0.44, \mathrm{p}=\right.$ $0.0002)$ and $24^{\circ} \mathrm{C}\left(r_{60}=0.26, p=0.044\right)$ when considering all individuals from each treatment together. These relationships were generally improved if each replicate aquarium was considered separately.

Since the exact lengths of the amphipods were unknown prior to experimentation, the positive rela- tionship between infection levels and size makes it appropriate to correct for size (number of metacercariae/mm amphipod) when infection levels between different experimental temperatures are compared. Such correction, however, causes no significant departure from the results depicted in Fig. 6. The ratio of infection levels between 24 and $22^{\circ} \mathrm{C}$ is 3.3 and 3.1 respectively prior to and following correction.

\section{Pathology and behavioural changes}

The bodies, especially the gills, of the amphipods appeared to be considerably more transparent in infected than in uninfected specimens (Fig. 7). Six people were asked to classify the photos of amphipod gills as 'transparent' or 'non-transparent'. This produced very similar results in that 85.7 to $91.4 \%$ of the gills from the group of Maritrema subdolum-infected specimens ( $n=35$ ) were declared 'transparent', whereas only 0 to $15.0 \%$ of gills from uninfected control individuals $(n=40)$ were classified so. This discrepancy was statistically significant (Mann-Whitney test, $Z=-2.91, p<0.004$ ) suggesting that the majority of variance in gill transparency can be explained by the trematode infection. Because the transparent gills contained only very little haemolymph, we interpret this transparency as parasite-induced anaemia.

Infection appears to affect the amphipod's surface activity at $24^{\circ} \mathrm{C}$ (Fig. 8); only 2 Corophium volutator specimens remained uninfected in the Maritrema subdolum-treated aquaria. The repeated-measures ANOVA for evaluation of the influence of treatment and date on the surface activity on Day 2 and Day 9 , showed a marginally significant 2-way interaction between treatment and date $\left(F_{1,6}=5.65, p=0.055\right)$. However, because the type II error can be substantial for an F-ratio based on 1 and 6 degrees of freedom, $H_{0}$ should not be accepted if the p-value for the interaction term is close to $5 \%$ (e.g. Underwood 1981) Hence, the proportion of surface-active amphipods exposed to parasites is here considered to increase between Day 2 and Day 9 as opposed to control individuals

\section{Mortality}

A 2-way ANOVA performed to evaluate the influence of temperature and treatment on the survival of Corophium volutator, showed a significant temperature and treatment interaction $\left(F_{2,24}=4.40, \mathrm{p}=0.024\right)$ As shown in Fig. 9, this interaction is likely to have been accomplished by temperature-independent survival at about $80 \%$ among controls, whereas increas- 

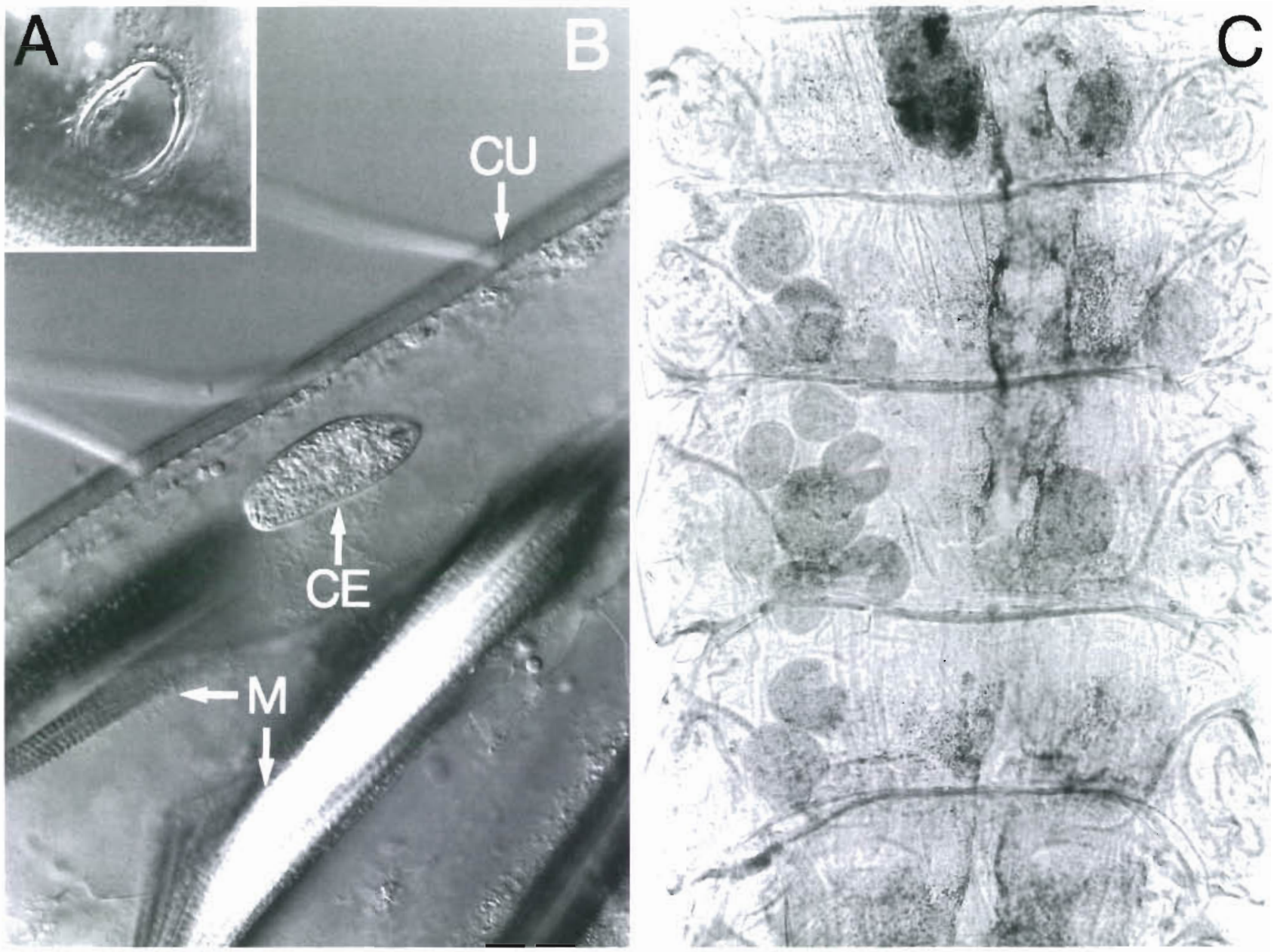

Fig. 5. Corophium volutator. (A) Section of a thoracical appendage showing a cercarial penetration site in the cuticula (differential interference contrast, DIC, $\times 270$ ). (B) Section of a thoracical appendage showing an unencysted tailless Maritrema subdolum cercaria (DIC, $\times 210)$. CU: cuticula, CE: cercaria, M: muscle fibre. (C) Ventral view of thoracic segments (with appendages removed) containing meso/metacercariae $(\times 85)$

ing temperature influenced an increasing mortality of parasite-exposed amphipods. A 1-way ANOVA performed on the controls alone confirmed that temperature had no significant impact on survival $\left(F_{2,11}=2.12\right.$. $\mathrm{p}=0.17$ ). Exposure to Maritrema subdolum-infected snails did not affect the survival of $C$. volutator at $15^{\circ} \mathrm{C}$ (none infected), whereas the parasites seriously compromised amphipod survival at increasing temperatures, inducing a mortality rate at $24^{\circ} \mathrm{C}$ above $50 \%$ in relation to controls

Inspection of dead amphipods from control aquaria revealed that the majority possessed wounds originating primarily from distortion of the outer segments of various appendages. This damage probably occurred during manipulation by pincers prior to experimentation, and may have contributed to the observed $20 \%$ mortality among control individuals.

\section{DISCUSSION}

\section{Temperature and mortality}

Present results demonstrate that larvae of Maritrema subdolum are a potential agent of significant additive mortality in Corophium volutator in a highly temperature-dependent manner. The similar temperaturedependent pattern in infection rates strongly suggests a causal connection between infection rate and mortality, which is consistent with many other investigated hostparasite associations (see Anderson \& May 1978, Anderson 1979, Dobson \& Keymer 1990). The temperaturedependent influence of the parasites most likely originates from the positive relationship between cercarial emergence and temperature. However, within the interval of 15 to $25^{\circ} \mathrm{C}$ this relationship is only slightly 


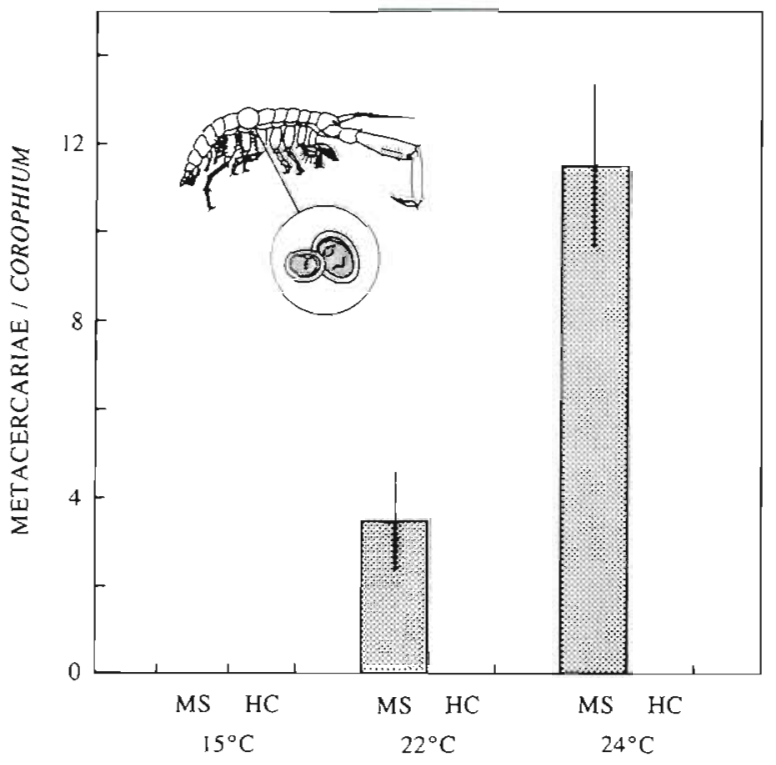

Fig. 6. Corophium volutator. Mean number $( \pm 1 \mathrm{SE})$ of metacercariae per amphipod per aquarlum as a function of temperature. Treatments: $\mathrm{MS}=$ addition of Maritrema subdolum infected snails; $\mathrm{HC}=$ addition of Himasthla continua infected snails (control) ( $\mathrm{n}=5$ aquaria, except for $\mathrm{MS} 24^{\circ} \mathrm{C}$ and $\mathrm{HC}$ $24^{\circ} \mathrm{C}$ where $\mathrm{n}=6$ and 4 , respectively). The difference between $\mathrm{MS} 22^{\circ} \mathrm{C}$ and $\mathrm{MS} 24^{\circ} \mathrm{C}$ was statistically significant (Student's $t$-test, $t_{9}=3.44, \mathrm{p}<0.01$ ) curvilinear (see Fig. 3) whereas a threshold temperature seems to occur within the narrow interval of 22 to $24^{\circ} \mathrm{C}$, above which the mortality is accelerated disproportionately (Fig 9). Although the estimates of cercarial production during the main experiment must be taken cautiously (see 'Materials and methods'), it is likely that temperature-dependent factors other than cercarial production affect the transmission success of the parasites. Such factors could be temperature-dependent swimming behaviour, penetration ability of the cercariae, or behavioural changes of the amphipod host facilitating transmission. Although these possibilities are not mutually exclusive, the present study is consistent with the latter possibility. Contact between larval trematodes and amphipods is likely to be accomplished primarily via the ventilation current of the amphipod. Moreover, ventilation rate in marine bottom-dwelling invertebrates generally increases with temperature (see Kristensen 1983, and references therein). Therefore, an additional increase in parasite burden can be expected with increasing temperatures even with a constant density of cercariae in the water. The reason for the observed positive relation between infection rate and size may also be the resuit of size-dependent ventilation volume.

Infestation seems to induce anaemia in Corophium volutator as assessed from the transparent appearance
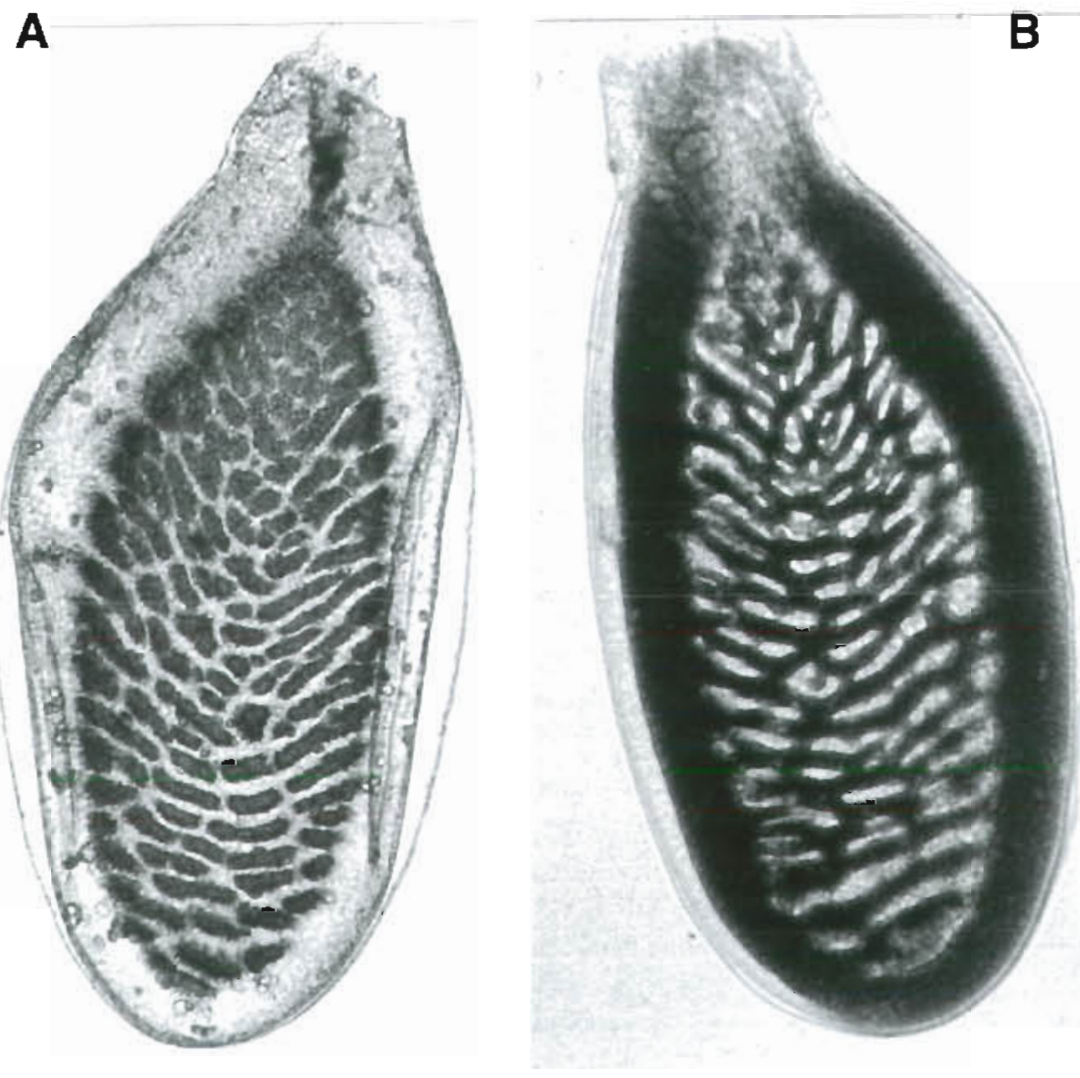

Fig. 7. Corophium volutator Hindmost gill from (A) a Maritrema subdolum-infected specimen showing advanced anaemia, and (B) a normal gill from an uninfected individual $(\times 200)$ 


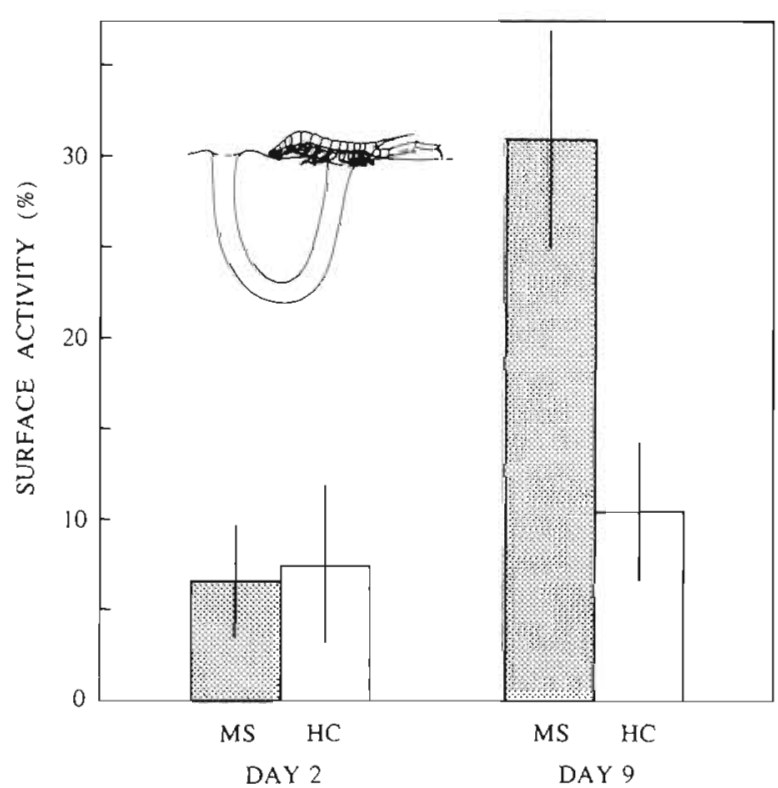

Fig. 8. Corophium volutator. Mean (\%) surface activity $( \pm 1 \mathrm{SE})$ of amphipods in experimental aquaria at $24^{\circ} \mathrm{C}$ at initiation (Day 2) and at termination (Day 9) of the main experiment. Number of experimental units (aquaria) and treatment abbreviations as in Fig. 6

of the amphipods' gills due to lack of haemolymph. Anaemia causes reduced efficiency of oxygen uptake which, in turn, may further increase ventilation activity and thereby probably also infection rate, as argued above. As would happen during environmentally caused oxygen depletion in bottom waters (e.g. Jørgensen 1980), difficulties of oxygen extraction may ultimately force the animals to leave their burrows in pursuit of higher axygen tensions. The seemingly higher surface activity among Maritrema subdolumexposed amphipods than among control individuals is consistent with this.

Whether or not infliction of anaemia in the amphipods is a parasite strategy evolved in order to promote transmission of metacercariae to the shorebird final host, it is likely to be advantageous to the parasites. Since most shorebirds prefer to locate their prey by visual means rather than by tactile detection through penetration of the substrate (e.g. Evans 1986, Mouritsen 1993), an elevated surface activity among infected Corophium volutator specimens is likely to promote transmission.

\section{Type of mortality}

Holmes (1982) argued that laboratory experiments on the influence of parasites on host survival are prone

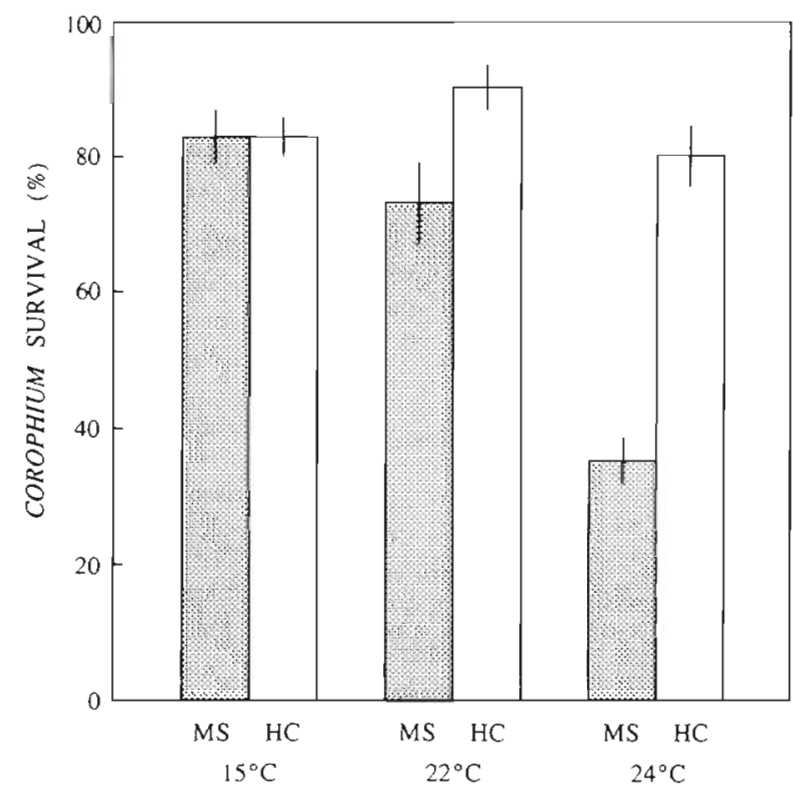

Fig. 9. Corophium volutator. Mean (\%) survival rates ( \pm 1 SE) of amphipods exposed to different experimental temperatures and treatments. n-Values and abbreviations as in Fig. 6. Treatments were compared pair-wise at each temperature by Mann-Whitney tests. $15^{\circ} \mathrm{C}: Z=-0.106, p=0.92$ (non-significant); $22^{\circ} \mathrm{C}: Z=-2.23, \mathrm{p}=0.03 ; 24^{\circ} \mathrm{C}: Z=-2.58, \mathrm{p}<0.001$

to infer the induced mortality as purely an addition to the mortality in control groups of animals. Yet, the effect of parasites in the field may be compensatory, in that they affect hosts that would have died anyway from other causes. If this applies to the presently studied host-parasite interaction, no population dynamic consequences should be expected from the presence of microphallid trematodes in a natural population of Corophium volutator. The present experimental results, however, are supported by a field study describing the extinction of a normally dense, agestructured and reproducing population of $C$. volutator as the likely result of the natural occurrence of these parasites (Jensen \& Mouritsen 1992). In both the laboratory and the field, the mortality occurred over a rather short period of time and, regarding the field study, during a season where other conceivable mortality factors, such as bad weather conditions, pollutants, toxic algae, invertebrate and vertebrate predators, were weak or absent (Jensen \& Mouritsen 1992, unpubl. data). These circumstances suggest parasiteinduced additive rather than compensatory mortality in infected natural C. volutator populations. In such populations the parasite-induced mortality can even be expected to have depensatory (sensu Holmes 1982) properties due to the parasite-induced increase in amphipod surface activity. Such elevation of prey availability is likely to attract more feeding shorebirds 
during seasons where they are present (Boates \& Smith 1989, Mouritsen 1994) which, all other things being equal, must increase the predation pressure on also uninfected amphipods thereby exerting further mortality on the population

Readers of our previous paper (Jensen \& Mouritsen 1992) will know that 2 species of microphallid trematodes (Maritrema subdolum and Microphallus claviformis) were involved in the above mentioned field mortality of Corophium volutator. It should therefore be emphasized that preliminary experimental results do not suggest any important difference between the 2 species regarding their ability to induce mortality in C. volutator (Jensen 1996).

\section{Pathology}

Few studies have adequately described the pathological effects of trematodes in marine crustaceans (Meyer 1990), and the cause of death in infested Corophium volutator specimens remains somewhat elusive. Although disruption of nervous innervation to vital organs or obstruction of the digestive tract have been suggested (Lauckner 1987. Meyer 1990), the observed gill anaemia, which to our knowledge has not been described in the context of trematode-infection previously, could be an additional mortality factor induced perhaps by loss of body fluid through the penetration holes (Fig. 5A), absorption of these fluids by the growing meso/metacercariae, and/or direct obstruction of haemolymph flow by the cysts. Difficulties in osmoregulation or a secondary invasion of protozoans or bacteria due to the perforated cuticula may have similar deleterious effects.

\section{Stability of the host-parasite association}

The parasites' influence on the host population may be inferred from theoretical considerations (Anderson \& May 1978, May \& Anderson 1978, 1979. Anderson 1979, 1991, May 1983). A regulatory role of the parasites in stabilizing the dynamics of the host-parasite association is expected to be governed among other. things by overdispersion of parasite numbers per host (i.e. few host individuals harbour the majority of the parasite population) and density-dependent host mortality (e.g. malnutrition of host specimens at high densities promoting infection). In contrast, random distribution of the parasites per host, density-independent host mortality, and time delays in the development of infective stages of the parasite are processes that may destabilize the interaction and so cause fluctuations in the host population.
Most known host-parasite associations show stabiliz ing as well as destabilizing elements (May \& Anderson 1978, Anderson 1979), and the present Corophium volutator-Maritrema subdolum association is no exception. However, the only stabilizing property of the interaction that can be inferred from the present results is the overdispersed parasite distribution. The sizedependent parasite burden with perhaps a size-dependent resistance to parasite-induced pathology may explain this effect. Also the expectation that reinfection is facilitated by parasite-induced increases in ventilation rate could reinforce overdispersion. Regardless of how overdispersion is accomplished, the stabilizing property of overdispersed parasite distribution is based on the assumption that heavily infected hosts exhibit disproportionally high mortality rates causing also the death of the parasites they contain.

Disregarding overdispersion, the life-cycle of the trematodes itself, however, suggests merely an unstable interaction. First, the parasite burden in Corophium volutator must depend on the density of sympatric parasitized Hydrobia ulvae, the first intermediate host, everything else being equal. Hence, the parasite burden in $C$. volutator need not be related to current amphipod density. Second, the life cycle is completed in intertidal habitats that are utilized by the shorebird primary host mainly during autumn and spring migration (Laursen \& Frikke 1984, Smit \& Piersma 1989). The parasite prevalence in a given snail population (and hence the infection level in sympatric amphipods) is therefore likely to depend on the transmission between infected amphipods and birds on other sites along the east-atlantic flyway rather than the local amphipod population (K. N. Mouritsen, K. T. Jensen \& T. Jensen unpubl.). Third, because of a considerable development time of larval trematodes within the snails (months, see Jensen \& Mouritsen 1992), the migratory behaviour of the final hosts cause a destabilizing time-lag between the development of larval stages and parasite reproduction. Finally and perhaps most importantly, the temperature may exert considerable control over the abundance of released infective stages and thus the mortality within the population of the second intermediate host. Even a relatively small temperature increase seems able to overcome the buffering effect of a basically overdispersed parasite distribution and invoke substantial mortality. To the extent that weather conditions are unpredictable, such temperature dependence may in itself give rise to largely unpredictable mortalities or epizootics inherently independent of current host density.

Temperature-dependent infection rates, time delays in the parasite's life cycle, and tendency toward density independence point to at least periodic parasiteinduced instability in the host population rather than 
stable regulation. In principle, this should increase the probability of trematode-induced epizootics in natural populations of Corophium volutator, causing these parasites to have significant population dynamic consequences. We suggest that our finding of a collapse in a local population of $C$. volutator (Jensen \& Mouritsen 1992) should be viewed in this context. Although there are many reasons other than parasites why population abundances might show wide fluctuations, parasitic infestation might well be the cryptic mortality agent behind some of the previous more or less unexplained observations of erratic fluctuations in $C$. volutator abundance, including occasional local extinction (see Watkin 1941, Muus 1967, Reise 1978, 1985, Fish \& Mills 1979, Möller \& Rosenberg 1982, Murdoch et al. 1986, Olafsson \& Persson 1986, Wilson 1989, Matthews et al. 1992). We therefore recommend that the influence of parasites also be considered when the population dynamic of amphipods or other soft-bottom invertebrates is investigated in marine habitats.

Acknowledgements. We are indebted to Anni $\mathrm{H}$. Jensen for technical assistance, and to Dr J. Boomsma, Prof. F. B. Christensen and referees for valuable comments on an earlier draft. The study was supported by Aarhus University Research Foundation (technical equipment) and the Carlsberg Foundation (grant to K.N.M.).

\section{LITERATURE CITED}

Ambrose WG Jr (1984) Influence of predatory polychaetes and epibenthic predators on the structure of a soft-bottom community in a marine estuary. J Exp Mar Biol Ecol 81: $115-145$

Ambrose WG Jr (1991) Are infaunal predators important in structuring marine soft-bottom communities. Am Zool 31: $849-860$

Anderson RM (1979) The influence of parasitic infection on the dynamics of host population growth. In: Anderson RM, Turner BD, Taylor LR (eds) Population dynamics. 20th Symp British Ecological Soc, London 1978. Blackwell Scientific Publications, Oxford, p 245-281

Anderson RM (1991) Populations and infectious diseases: ecology or epidemjology? J Anim Ecol 60:1-50

Anderson RM, Gordon DM (1982) Processes influencing the distribution of parasite numbers within host populations with special emphasis on parasite-induced host mortalities. Parasitology 85:373-398

Anderson RM, May RM (1978) Regulation and stability of host-parasite population interactions. I. Regulatory processes. J Anim Ecol 47:219-247

Boates JS, Smith PC (1989) Crawling behaviour of the amphipod Corophium volutator and the foraging by Semipalmated Sandpipers, Calidris pusilla. Can J Zool 67: $457-462$

Commito JA (1982) Importance of predation by infaunal polychaetes in controlling the structure of a soft-bottom community in Maine, USA. Mar Biol 68:77-81

Curtis LA. Hubbard KM (1990) Trematode infections in a gastropod host misrepresented by observing shed cercariae J Exp Mar Biol Ecol 143:131-137
Day RW, Quinn GP (1989) Comparisons of treatments after an analysis of variance in ecology. Ecol Monogr 59:433-463

Deblock S (1980) Inventaire des trématodes larvaires parasites des mollusques Hydrobia (Prosobranches) des côtes de France. Parassitologia 22:1- 105

de Wilde PA, Berghuis EM (1978) Cyclic temperature fluctuations in a tidal mud-flat. In: Naylor E, Hartnoll RG (eds) Cyclic phenomenon in marine plants and animals. Pergamon Press, Oxford, p 435-441

Dobson AP, Hudson PJ (1986) Parasites, disease and the structure of ecological communities. Trends Ecol Evol 1:11-15

Dobson AP, Keymer AE (1990) Population dynamics and community structure of parasite helminths. In: Shorrocks B. Swingland IR (eds) Living in a patchy environment. Oxford University Press, Oxford, p 107-125

Esch GW, Fernández CF (1993) A functional biology of parasitism. Chapman and Hall, London

Evans A (1986) Experimental evidence for the use of visual cues by foraging Dunlins. Wader Study Group Bull 48: $14-15$

Fish JD, Mills A (1979) The reproductive biology of Corophium volutator and $C$. arenarium (crustacea: amphipoda). J Mar Biol Assoc UK 59:355-368

Ginetsinskaya TA (1988) Trematodes, their life-cycles, biology and evolution. Amerind Publication Company, New Delhi

Hamilton WD, Axelrod R, Tanese R (1990) Sexual reproduction as an adaptation to resist parasites (a review). Proc Nat Acad Sci USA 87:3566-3573

Holmes JC (1982) Impact of infectious disease agents on the population growth and geographical distribution of animals. In: Anderson RM, May RM (eds) Population biology of infectious diseases, Dahlem Konferenzen 1982 Springer Verlag, Berlin, p 37-51

Holt RD (1993) Infectious diseases of wildlife, in theory and in practice. Trend Ecol Evol 8:423-425

Hull CH, Nie NH for release 7-9. McGraw-Hill, New York

Jensen KT, Mouritsen KN (1992) Mass mortality in two common soft-bottom invertebrates, Hydrobia ulvae and Corophium volutator - the possible role of trematodes. Helgol Meeresunters 46:329-339

Jensen $T$ (1996) The influence of microphallid trematodes on the host organisms Corophium volutator and $C$. arenarium. MSc thesis, Univ. of Aarhus

Jorgensen BB (1980) Seasonal oxygen depletion in the bottom waters of a Danish fjord and its effects on the benthic community. Oikos 34:68-76

Kent AC, Day RW (1983) Population dynamics of an infaunal polychaete: the effect of predators and an adult-recruit interaction. J Exp Mar Biol Ecol 73:185-203

Kinne $O$ (1980) Diseases of marine animals, Vol 1. Biologische Anstalt Helgoland, Hamburg

Kinne O (1983) Diseases of marine animals, Vol 2. Biologische Anstalt Helgoland, Hamburg

Kristensen E (1983) Ventilation and oxygen uptake by three species of Nereis (Annelida: Polychaeta). II. Effects of temperature and salinity changes. Mar Ecol Prog Ser 12: $299-306$

Lafferty KD (1992) Foraging on prey that are modified by parasites. Am Nat 140:854-867

Lauckner G (1987) Effects of parasites on juvenile Wadden Sea invertebrates. In: Tougaard S, Asbirk S (eds) Proc 5th Int Wadden Sea Symp. The National Forest and Nature Agency and the Museum of Fisheries and Shipping, Esbjerg, p 103-121

Laursen K. Frikke J (1984) The Danish Wadden Sea. In: Evans PR, Goss-Custard JD, Hale WG (eds) Coastal waders and 
wildfowl in winter Cambridge University Press, Cambridge, p 214-223

Lively CM (1992) Parthenogenesis in a freshwater snail: reproductive assurance versus parasitic release. Evolution 46:907-913

Lively CM, Craddock C, Vrijenhoek RC (1990) Red Queen hypothesis supported by parasitism in sexual and clonal fish. Nature 344:864-866

Matthews SL, Boates JS, Walde SJ (1992) Shorebird predation may cause discrete generations in an amphipod prey. Ecography 15:393-400

May RM (1983) Parasitic infections as regulators of animal populations. Am Sci 71:36-45

May RM, Anderson RM (1978) Regulation and stability of host-parasite population interactions. II. Destabilising processes. J Anim Ecol 47:249-267

May RM, Anderson RM (1979) Population biology of infectious diseases: II. Nature 280:455-461

Meyer TR (1990) Diseases caused by protistans and metazoans. In: Kinne $\mathrm{O}$ (ed) Diseases of marine animals, Vol 3. Biologische Anstalt Helgoland, Hamburg, p 350-423

Minchella DJ, Scott ME (1991) Parasitism: a cryptic determinant of animal community structure. Trend Ecol Evol 6:250-254

Moller AP (1990) Parasites and sexual selection: current status of the Hamilton and Zuk hypothesis. J Evol Biol 3:319-328

Möller P, Rosenberg R (1982) Production and abundance of the amphipod Corophium volutator on the west coast of Sweden. Neth J Sea Res 16:127-140

Mouritsen KN (1993) Diurnal and nocturnal prey detection by Dunlins Calidris alpina. Bird Study 40:212-215

Mouritsen KN (1994) Day and night feeding in Dunlins Calidris alpina: choice of habitat, foraging technique and prey. J Avian Biol 25:55-62

Murdoch MH, Bärlocher F, Laltoo ML (1986) Population dynamics and nutrition of Corophium volutator (Pallas) in the Cumberland Basin (Bay of Fundy). J Exp Mar Biol Ecol 103:235-249

Muus BJ (1967) The fauna of Danish estuaries and lagoons. Distribution and ecology of dominatung species in the shallow reaches of the mesohaline zone. Medd Dan Fisk Havunders 5:3-316

Olafsson EB, Persson LE (1986) The interaction between Nereis diversicolor O. F. Müller and Corophium volutator Pallas as a structuring force in a shallow brackish sediment. J Exp Mar Ecol Biol 103:103-117

Peer DL, Linkletter LE, Hicklin PW (1986) Life history and reproductive biology of Corophium volutator (Crustacea: Amphipoda) and the influence of shorebird predation on

This article was submitted to the editor population structure in Chignecto Bay, Bay of Fundy, Canada. Neth J Sea Res 20:359-373

Price PW (1980) Evolutionary biology of parasites. Princeton University Press, Princeton Quammen ML (1984) Predation by shorebirds, fish, and crabs on invertebrates in intertidal mudflats: an experimental test. Ecology 65: $529-537$

Reise K (1978) Experiments on epibenthic predation in the Wadden Sea. Helgol Wiss Meeresunters 31:55-101

Reise K (1985) Tidal flat ecology. An experimental approach to species interactions. Springer-Verlag, Berlin

Rohde K (1982) Ecology of marine animals. University of Queensland Press, Brisbane

Schneider D (1978) Equalisation of prey numbers by migratory shorebirds. Nature 271:353-354

Scott ME, Dobson A (1989) The role of parasites in regulation host abundance. Parasitol Today 5:176-183

Shaw RG, Mitchell-Olds T (1993) ANOVA for unbalanced data: an overview. Ecology 74:1638-1645

Smit CJ, Piersma T (1989) Numbers, midwinter distribution, and migration of wader populations using the East Atlantic Flyway. In: Boyd H, Pirot JY (eds) Flyways and reserve networks for waterbirds. International Waterfowl and Wetlands Research Bureau Spec Public No. 9. Canadian Wildlife Service, Ottawa, p 24-63

Sousa WP (1983) Host life history and the effect of parasitic castration on growth: a field study of Cerithidea californica Haldeman (Gastropoda: Prosobranchia) and its trematode parasites. J Exp Mar Biol Ecol 73:273-296

Sousa WP (1991) Cani models of soft-sediment community structure be complete without parasites. Am Zool 31. $821-830$

Théron A, Moné H (1984) Chronobiological aspects of the host-parasite relationships between Biomphalaria glabrata and Schistosoma mansoni: cercarial production and infectivity, and growth kinetics of the host. J Invert Pathol $44: 209-213$

Underwood AJ (1981) Techniques of analysis of variance in experimental marine biology and ecology. Oceanogr Mar Biol Annu Rev 19:513-605

Watkin EE (1941) The yearly life cycle of the amphipod, Corophium volutator. J Anim Ecol 10:77-93

Wilson WH Jr (1989) Predation and the mediation of intraspecific competition in an infaunal community in the Bay of Fundy. J Exp Mar Biol Ecol 1.32:221-245

Wilson WH Jr (1991) Competition and predation in marine soft-sediment communities. Annu Rev Ecol Syst 21: $221-241$

Manuscript first received: November 26, 1996

Revised version accepted: March 25, 1997 